\title{
Production of Transgenic Porcine Embryos Reconstructed with Induced Pluripotent Stem-Like Cells Derived from Porcine Endogenous Factors Using piggyBac System
}

\author{
Su-Jin Kim, ${ }^{1}$ Hee-Sun Kwon, ${ }^{1}$ Dae-kee Kwon, ${ }^{1}$ Ok-Jae Koo, ${ }^{2}$ Joon-Ho Moon, \\ Eun-Jung Park, Soo-Young Yum, ${ }^{1}$ Byeong-Chun Lee, ${ }^{1}$ and Goo Jang ${ }^{1,3,4}$
}

\begin{abstract}
The potential of induced pluripotent stem (iPS) cells, which have self-renewal ability and can differentiate into three germ layers, led us to hypothesize that iPS cells in pigs can be useful and suitable source for producing transgenic pigs. In this study, we generated iPS-like cells using doxycycline-inducible piggyBac $(P B)$ expression vectors encoding porcine 4 transcription factors. After transfection, transfected cells were cultured until the formation of outgrowing colonies taking least of 7-10 days. The iPS-like cells demonstrated pluripotent characteristics such as self-renewal, high proliferation, expression of pluripotent markers, and aggregation ability. The embryo development through somatic cell nuclear transfer (SCNT), cleavage rate, and blastocyst formation rate did not show any significant differences. However, the total cell number of blastocysts was significantly increased with the established cell line. In conclusion, the iPS-like cell line, generated from porcine transcriptional factors using the $P B$ transposon system, demonstrated pluripotency with the capacity for unlimited self-renewal, and could be used as donor cells to produce cloned embryos by SCNT. These cells will be suitable for gene modification and would contribute to the stability or safety of pig models in biomedical research.
\end{abstract}

Keywords: donor cells, induced pluripotent cells, piggyBac transposon, porcine transcription factors, somatic cell nuclear transfer

\section{Introduction}

$\mathbf{T}$ RANSGENIC PIGS ARE IMPORTANT for studying human diseases and cell therapy models (Aigner et al., 2010; Ekser et al., 2011, 2012). To produce highly efficient transgenic pigs, the somatic cell nuclear transfer (SCNT) technique has been widely used with genetically modified donor cells. In SCNT, somatic cells are needed for the donor cells to produce embryos. Nevertheless, the production efficiency of cloned embryos or animals using SCNT is lower than that observed using other in vitro production methods (Cibelli et al., 2002; Yang et al., 2007).

Many studies have been conducted to overcome this problem. Some of these studies have focused on donor cells to enhance the efficiency of SCNT (Tian et al., 2003). The strategies used in these studies include synchrony of the cell cycle stage (Campbell et al., 1994), age (Jeon et al., 2012; Wang et al., 2015), origin (Li et al., 2014; Richter et al., 2012), passage (Li et al., 2014), and type (Kim and Hyun, 2014). However, the conditions for donor cells have not been optimized for high-efficiency production, the $\mathrm{G}_{0}$ or $\mathrm{G}_{1}$ phase of the donor cell cycle, long telomere lengths, or early passage, which would reduce damage or mutations in the chromosome of origin and cells (Wilmut et al., 2007).

These conditions facilitate nuclear reprogramming during the developmental events in SCNT-cloned embryos and coordinate the interaction of the donor nucleus with the recipient cytoplasm (Campbell et al., 1996; Wells et al.,

\footnotetext{
${ }^{1}$ Department of Veterinary Clinical Sciences, College of Veterinary Medicine, Research Institute of Veterinary Science, Seoul National University, Seoul, Republic of Korea.

${ }^{2}$ ToolGen, Inc., Seoul, Republic of Korea.

${ }^{3}$ BK21 Plus program, College of Veterinary Medicine, Seoul National University, Seoul, Republic of Korea.

${ }^{4}$ Emergence Center for Food-Medicine Personalized Therapy System, Advanced Institutes of Convergence Technology, Seoul National University, Gyeonggi-do, Republic of Korea.
} 
2003). In particular, synchronizing the G1 and/or G0 phase of donor cells would generally be more suitable for reprogramming SCNT-derived embryos, and several studies have suggested using serum starvation or high-density cultured cells to synchronize the donor cell cycle stage to G1 and/or G0 for SCNT (Baguisi et al., 1999; Kasinathan et al., 2001; Polejaeva et al., 2000; Wakayama et al., 1998).

In contrast, since well-proliferated stem cells are highly activated stage to $\mathrm{M}$ phage, the stage is not suitable as SCNT donor cells to generate cloned embryos and animals (Oback and Wells, 2002). However, other studies that have recently used stem cells as donor cells for SCNT demonstrated that cloned embryos reconstructed with stem cells at the M phase develop more efficiently (Kou et al., 2010; Wakayama et al., 1999).

These studies reported the successful production of cloned embryos and animals from several stem cell types, and the rates of these cells appear to be higher than those of fully differentiated cells (Kou et al., 2010; Mizutani et al., 2016; Rideout et al., 2000; Wakayama et al., 1999; Zheng et al., 2009). These results suggest that undifferentiated donor cells may increase the developmental rate of embryos and the birth rate of cloned animals.

Although embryonic stem cells (ESCs) are well known, porcine ESCs have limited germline transmission (West et al., 2011). Induced pluripotent stem cells (iPSCs) have self-renewal ability and the potential for differentiation into the three germ layers, which may be useful as a novel tool for producing transgenic pigs (Hanna et al., 2007; Wu et al., 2011). iPSCs are artificial reverse-differentiated pluripotent cells produced through transcription of specific genes (Oct4, Sox2, Myc and Klf4) from fully differentiated cells. The iPSC technology was developed by Shinya Yamanaka (Takahashi and Yamanaka, 2006). Induced cell lines have various pluripotent characteristics such as self-renewal ability, expression of several pluripotent markers, teratoma formation, and differentiation into three germ layers.

Until recently, this innovative technology has been applied worldwide and in several species (Cao et al., 2012; Esteban et al., 2009; Ezashi et al., 2009; Han et al., 2011; Honda et al., 2010; Khodadadi et al., 2012; Kues et al., 2013; Liu et al., 2012; Song et al., 2013; Talluri et al., 2015; Whitworth et al., 2014; Wu et al., 2009), including humans (Park et al., 2008; Takahashi et al., 2007; Yu et al., 2007). Therefore, iPSCs have become an alternative to ESCs. Many studies have employed viral-mediated vectors to transfer exogenous transcription factors into adult cells for successful induction and regeneration (Ezashi et al., 2011; Fusaki et al., 2009; Imamura et al., 2012; Montserrat et al., 2011).
However, the use of viral-mediated vectors to induce pluripotent cells restricts their therapeutic usage because of mutation risks and the potential activation of oncogenes (Nakagawa et al., 2008). The applications of iPSCs have been evaluated in several species using adenoviral vectors (Zhou and Freed, 2009), episomal DNAs (Lorenzo et al., 2013), and small molecules (Esteban et al., 2009). Those were evaded into the host's chromosomal DNA. Using piggyBac $(P B)$ transposition reduces the risk of insertional mutagenesis, and is safer to deliver exogenous DNA than other gene delivery systems (Wu et al., 2006).

In addition to the absence of certain pig ESCs, there is no clear evidence that piPSCs are suitable as donor cells in SCNT. In this study, we used $P B$ transposon-inducible vector, which was constructed with four porcine transcriptional factors controlled by doxycycline, to induce undifferentiated cells. In addition, induced pluripotent stem (iPS)like cells were established, demonstrating pluripotency with self-renewal ability. Furthermore, SCNT-derived cloned embryos were evaluated for developmental competence using the iPS-like cells as donors.

\section{Materials and Methods}

\section{Chemicals and materials}

All chemicals were obtained from Sigma-Aldrich Co. LLC (Missouri) unless otherwise stated.

\section{Primary culture of porcine fetal fibroblasts}

Primary culture was performed using a 35-day fetus. Lumps of tissues from the backside of the fetus were minutely homogenized and cultured overnight in collagenase IV in an incubator at $37^{\circ} \mathrm{C}$. The homogenized tissues were washed more than three times with phosphate-buffered saline (PBS; Life Technologies, Carlsbad, CA) and collected by centrifugation at $1500 \mathrm{rpm}$ for 2 minutes. The collected clusters of cells were cultured in 60-mm culture dishes with Dulbecco's Modified Eagle's medium (DMEM; Life Technologies), supplemented with $10 \%$ fetal bovine serum (FBS; Life Technologies) and 1\% Pen Strep (Life Technologies).

\section{Transcriptional factors cloning and expression vector construction}

The coding domain regions of porcine Oct4 (Kim et al., 2015), Sox2, Myc, and Klf4 were amplified from pig ovarian cDNA by PCR and cloned to TA-vectors using designed cloning primers (Table 1). Among the attained porcine transcription factors, Oct, Sox2, and Myc (pOSM) were

Table 1. Primer Sequences of Pig Transcription Factors

\begin{tabular}{lll}
\hline Primer name & \multicolumn{1}{c}{ Sequence } & Reference \\
\hline CDS- oct 4 & F: ATGGCGGGACACCTGGCTTCCGACTT & ENSSSCT \\
CDS- Sox 2 & R: TCTGGGCTCCCCCATGCATTCAAACTGA & 00000001516 \\
& F: ATGTACAACATGATGGAGACGGAGCTGAAGC & ENSSSCT \\
CDS- $M y c$ & R: TCACATGTGAGAGAGAGGCAGTGTACCGTTGATG & 00000012883 \\
CDS- Klf4 & F: ATGCCCCTCAACGTCAGCTTCA & ENSSSCT \\
& R: TTATGGGCAAGAGTTCCGTAGCTGT & 00000006548 \\
& F: ATGGCTGTCAGCGACGCACT & ENSSST \\
& R: TTAAAAGTGCCTCTTCATGTGTAAGGCAAGG & 00000032943 \\
\hline
\end{tabular}


A

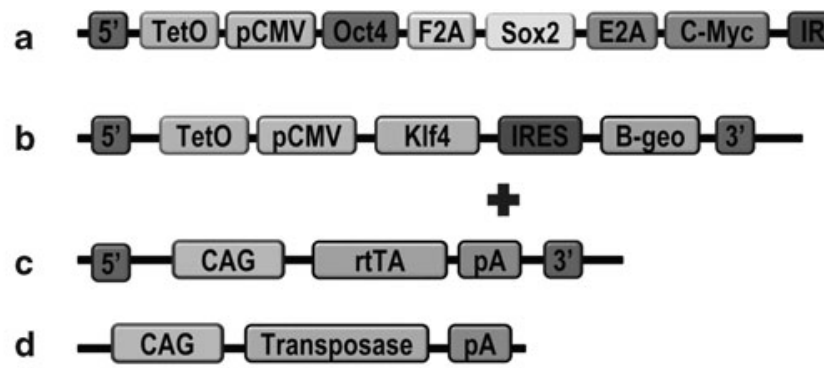

FIG. 1. Transcription factors containing piggyBac vector constructs [A, three porcine transcription factors (Oct4, Sox2, and cMyc) were linked by $2 \mathrm{~A}$ peptide (a) and Klf4 was individually cloned (b). Reverse tetracyclinecontrolled transactivator (rtTA) was cloned into piggyBac vector (c) and transposase was cloned into simple plasmid (d)] and first generated colony (B-a) and timely single-cell-derived colonies (B-b, $\mathbf{c}$ and d). Cells make clusters after 710 days of transfection (B-a). After single cell subculture on CF1 feeder, the cell formed shiny and tiny colonies at 12 hours (B-b); each single cell grew to certain size with more clear margins and dome-like shape, as time followed (B-c, d). Single cell cultured iPS-like cell line after GFP transfection for 12-72 hours (C). GFP transfected iPS-like cells on brightness $\left(\mathbf{a}-\mathbf{a}^{\prime \prime}\right)$, expression GFP on fluorescence $\left(\mathbf{b}-\mathbf{b}^{\prime \prime}\right)$ and 72 hours cultured $\left(\mathbf{c}, \mathbf{c}^{\prime}\right)$. GFP, green fluorescence protein; iPS, induced pluripotent stem.
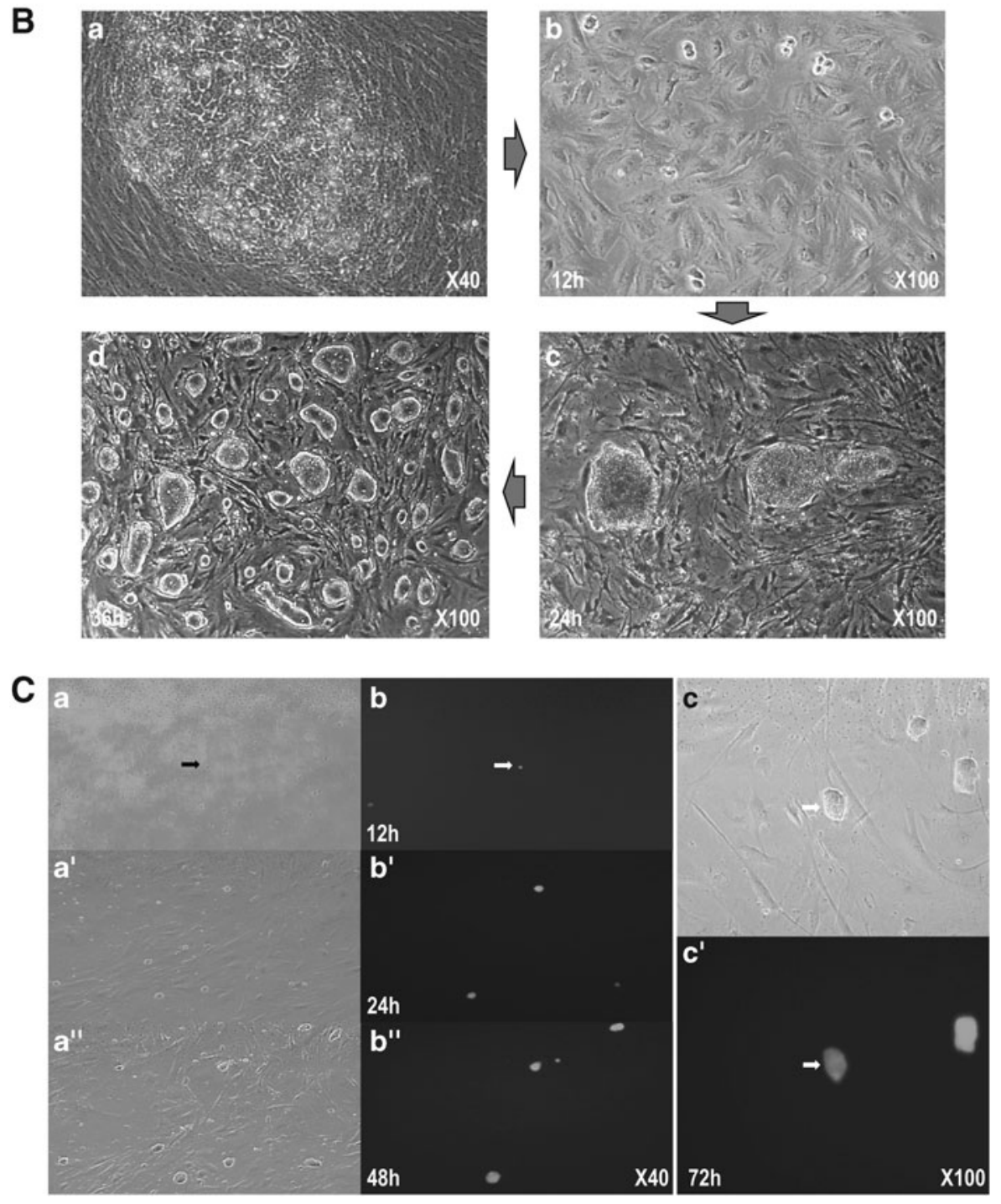

linked by 2A peptides (F2A and E2A) except for porcine Klf4 (pKlf4), which was individually constructed.

To design $P B$ expression vectors, targeted PCR DNA fragments were used for the Gateway Cloning System (Invitrogen, Carlsbad, CA) according to protocol. Targeted exogenous DNAs were amplified using PCR primercontaining Gateway sequence (F: attB1+kozak sequence and R: attB2, Supplementary Table S1; Supplementary Data are available online at www.liebertpub.com/cell). Amplified fragments were recombined with $\mathrm{BP}$ and LR clonase (Invitrogen). In this study, pDonor vector (Invitrogen) was used as an entry vector and PB-TET, which has an inducible expression system containing the tetracycline-dependent mini-CMV promoter from Addgene (www.addgene.org), was used as a final destination expression vector.

\section{Transfection of constructed PB vectors}

One day before transfection, fibroblasts were plated at a density of $1 \times 10^{5}$ cells $/ \mathrm{mL}$ in a well of six-well plate and cultured overnight to achieve $50 \%-70 \%$ confluence. Next, in total $2 \mu \mathrm{g}$ of constructed expression vector (Fig. 1A, a: PB-TET-pOSM, b: PB-TET-pKlf4, c: PB-CA-rtTA, and d: pCy43 [Sanger Institute, Hinxton, United Kingdom]), $6 \mu \mathrm{L}$ 
of the transfection reagent (Fugene HD; Roche, Inc., Switzerland), and $92 \mu \mathrm{L}$ of DMEM were incubated for $\sim 20$ minutes at room temperature (RT) in a $1.5-\mathrm{mL}$ tube, and were then overlaid on the prepared porcine fibroblasts. After 24 hours of transfection, $2 \mu \mathrm{g} / \mathrm{mL}$ doxycycline was added to DMEM/F12 (Life Technologies) culture media containing $15 \%$ FBS and $10 \mathrm{ng} / \mathrm{mL}$ basic fibroblast growth factor (bFGF), and transfected cells were cultured until the formation of cell colonies.

\section{Formation of iPS-like cells and culture}

iPS-like cells were cultured in stem cell culture media (DMEM/F12) containing 15\% FBS, $10 \mathrm{ng} / \mathrm{mL}$ bFGF, $1 \%$ Pen Strep, and $2 \mu \mathrm{g} / \mathrm{mL}$ doxycycline, and maintained with mitomycin C (MMC)-treated CF1 feeder cells. In subculture process, iPS-like colonies were manually picked using a fine capillary pipette and collected in a 1.5 -mL tube containing $1 \mathrm{~mL}$ Tryple (Invitrogen). The collected colonies were digested for 2-3 minutes in an incubator at $37^{\circ} \mathrm{C}$. After digestion, cells were collected by centrifugation at $1500 \mathrm{rpm}$ for 2 minutes, resuspended in stem cell culture media, and subcultured in a four-well dish on a feeder cell layer every 2 days. Cryopreservation was performed under liquid nitrogen using $70 \%$ culture medium with $20 \%$ FBS and $10 \%$ dimethyl sulfoxide.

\section{Colony formation on different culture media conditions}

To determine the optimal culture media conditions for maintaining pluripotency, generated iPS-like cells were cultured in different culture media. Well-growing iPS-like cells in control media (DMEM/F12 + 10 ng bFGF + Doxy $\left.^{+}\right)$ were transferred to (1) media with leukemia inhibitory factor (LIF) $\left(\mathrm{DMEM} / \mathrm{F} 12+10 \mathrm{ng}\right.$ humanLIF $\left.+\mathrm{Doxy}^{+}\right)$and (2) media without doxycycline (DMEM/F12 + 10 ng bFGF + Doxy"), and then cultured for 24 hours. We observed the morphology change of the iPS-like colonies at 12 and 24 hours.

\section{Additional transfection of reporter gene to iPS-like cells}

To confirm that the colonies were formed from single cells, PB-CA-GFP [a transposon vector that expresses green fluorescence protein (GFP) from a CMV early enhancer/ chicken $\beta$ actin (CAG) promoter] (Kim et al., 2011) was transfected into cells of the colonies using transfection reagent (Fugene HD). One day before transfection, the colonies were subcultured on CF1 feeder cells in a new four-well dish and cultured overnight. On the following day, $1 \mu \mathrm{g}$ of the constructed vector was mixed with $3 \mu \mathrm{L}$ of Fugene HD and $96 \mu \mathrm{L}$ of DMEM, incubated for $\sim 20$ minutes at RT in a 1.5$\mathrm{mL}$ tube, and overlaid on the colonies.

After 24 hours of transfection, the colonies were subcultured in stem cell culture media. To establish stable GFPexpressing cells, only GFP-expressing colonies were selected and subcultured manually. Moreover, red fluorescence protein (RFP)-expressing cells were established following the same procedures using the PB-CA-DsRed II vector, which expresses RFP from the CAG promoter.

\section{Alkaline phosphatase staining and CDy1 staining}

To determine the existence of pluripotent cell surface marker of transfected cells, the cells were stained with alkaline phosphatase (AP), using AP staining kit (Vector Laboratories, Bur- lingame, CA) and CDy1 (Active motif, Carlsbad, CA) staining according to manufacture's protocol (Kang et al., 2011).

\section{Immunocytochemistry of pluripotent markers}

To determine the location of Oct4 and Sox 2 protein expression, the cells were immunostained. The cells were fixed in $4 \%$ paraformaldehyde for 20 minutes, permeabilized with $0.1 \%$ Triton X-100 (Sigma) for 10 minutes, and blocked with $10 \%$ normal goat serum for 1 hour. The fixed cells were incubated in a refrigerator at $4^{\circ} \mathrm{C}$ overnight with primary antibodies (Oct3/4; Santa Cruz Biotechnology, Inc., CA, Sox 2; R\&D System, Minneapolis, MN, SSEA-1, 4 and Nanog; Millipore, 1:2000), followed by secondary antibodies (Cy3-AffiniPure Goat Anti-Mouse IgG, Jackson ImmunoResearch Laboratories, Inc., PA, 1:5000) for 2 hours. In addition, DAPI was used as a counterstain. The stained cells were examined under ultraviolet light using a fluorescence microscope (Nikon, Japan).

\section{Generation of chimeric parthenotes by iPS-like cells aggregation}

To determine the pluripotency of the cells, chimeric embryos were generated through iPSCs aggregation with parthenote blastomeres (Nakano et al., 2013). Established RFP-expressing iPS-like cells were used to generate chimeric embryos by injecting 15-20 RFP-expressing iPS-like cells to a 4-8 cell electro-activated parthenote using a fine injection needle attached to a micromanipulator.

The parthenotes were prepared 2 days in advance by electronic activation following the same protocol as the activation process described for SCNT (described below). The cell-injected parthenotes were cultured in porcine zygote medium-5 (PZM-5; Funakoshi Corporation, Tokyo, Japan) for 7 days and observed under ultraviolet light using a fluorescent microscope (Nikon, Japan). In addition, the aggregated and hatched blastocysts were seed cultured on a MMCtreated feeder cell layer. The obtained trophoblasts were stained using a $\beta$-gal staining kit (Invitrogen) according to the manufacturer's protocol.

\section{SCNT and embryo culture}

To produce cloned porcine embryos, SCNT was performed as previously described (Park et al., 2014). Initially, porcine ovaries were collected from a slaughterhouse in $0.9 \%(\mathrm{w} / \mathrm{v}) \mathrm{NaCl}$ solution at $30-37^{\circ} \mathrm{C}$. Antral follicles (3-6 $\mathrm{mm}$ ) were aspirated using an 18-gauge needle attached to a $10-\mathrm{mL}$ syringe and collected in a conical tube at $39^{\circ} \mathrm{C}$. A few minutes later, the sediment was washed with Dulbecco's PBS (Invitrogen) containing 1\% Pen Strep. Cumulusoocyte complexes (COCs) with intact compact cumulus cell layers were selected and washed three times in TCM-Hepes before being transferred to a modified TCM-199 supplemented with $10 \mathrm{ng} / \mathrm{mL}$ EGF, $0.57 \mathrm{mM}$ cysteine, $0.91 \mathrm{mM}$ sodium pyruvate, $5 \mu \mathrm{g} / \mathrm{mL}$ insulin, $1 \%$ (v/v) Pen Strep, $0.5 \mu \mathrm{g} / \mathrm{mL}$ follicle-stimulating hormone, $0.5 \mu \mathrm{g} / \mathrm{mL}$ luteinizing hormone, and $10 \%$ porcine follicular fluid.

After 22 hours of culture, the cultured COCs were moved to in vitro maturation (IVM) medium without gonadotropin for additional 22 hours. The COCs were cultured at $38^{\circ} \mathrm{C}$ with $5 \% \mathrm{CO}_{2}$. After 44 hours of maturation, the cumulus 
cells of the COCs were removed by pipetting with $0.1 \%$ hyaluronidase in TCM-Hepes.

To prepare donor cells, iPS-like cells were subcultured or thawed on MMC-treated CF1 feeder cells 2 days before SCNT. Subsequently, colonies were manually picked using a fine capillary pipette and collected in $1.5-\mathrm{mL}$ tubes containing $1 \mathrm{~mL}$ Tryple (Invitrogen) solution. The colonies were enzymatically digested for 2-3 minutes in an incubator at $37^{\circ} \mathrm{C}$. The digested cells were collected by brief centrifugation, resuspended in modified Tyrode's albumin lactate pyruvate (TALP)-Hepes, and stored at RT. The solution contained a mix of prepared cells and some CF1 feeder cells; however, both types of cells were easily distinguished by their morphology and size.

Matured oocyte stained with $5 \mu \mathrm{g} / \mathrm{mL}$ bisbenzimide (Hoechst 33342) for 10 minutes and observed under an inverted microscope equipped with epifluorescence at $200 \times$ magnification. Each matured oocyte was held with holding micropipette $(150 \mu \mathrm{m}$ inner diameter $)$, and then enucleated with a micromanipulator (Nikon-Narishige, Tokyo, Japan) in TALP with $5 \mu \mathrm{g} / \mathrm{mL}$ cytochalasin B. The first polar body and adjacent cytoplasm, containing the metaphase-II chromosomes, were aspirated using a fine micropipette. The enucleated oocytes were placed in TALP-Hepes and used for SCNT. Transfected cells were used as donor cells for SCNT. The donor cells were injected into the perivitelline space of the enucleated oocytes and electrically fused using an electro cell fusion generator (LF101; Nepa Gene Co., Japan).

After 40 minutes of fusion, the fused embryos were artificially activated with a single direct current pulse of
$1.5 \mathrm{kV} / \mathrm{cm}$ for $60 \mu \mathrm{sec}$ using BTX Electro Cell Manipulator 2001 (BTX, Inc., San Diego). The activated SCNT embryos were cultured in PZM-5 (Yoshioka et al., 2002) covered with mineral oil at $39^{\circ} \mathrm{C}$ in $5 \% \mathrm{CO}_{2}, 5 \% \mathrm{O}_{2}$, and $90 \% \mathrm{~N}_{2}$. The embryos were evaluated for cleavage on day 2 and blastocyst formation from days 5 to 7 , and the total cell number of cloned blastocysts was counted on day 7. In addition, some of the cloned blastocysts were stained using a $\beta$-gal staining kit (Invitrogen). To compare within the established iPS-like cell line and normal porcine fetal fibroblasts (PFFs), a general SCNT procedure was performed with the PFFs.

\section{Statistical analysis}

All experiments were replicated at least three times and statistically analyzed using Prism 5 software (GraphPad, La Jolla, CA). Student's $t$-test was used to determine any differences between two groups. A $p$-value of $<0.05$ was considered statistically significant.

\section{Results}

\section{Colony formation and single cell-driven culture}

From day 10, iPS-like colonies were formed in different spots (Fig. 1B-a), then after culturing on MMC-treated CF1 feeder cells. After 12 hours, the subcultured cells adhered onto feeder cells as tiny colonies (Fig. 1B-b). After 24 hours of subculture, the colonies grown had a clear margin and
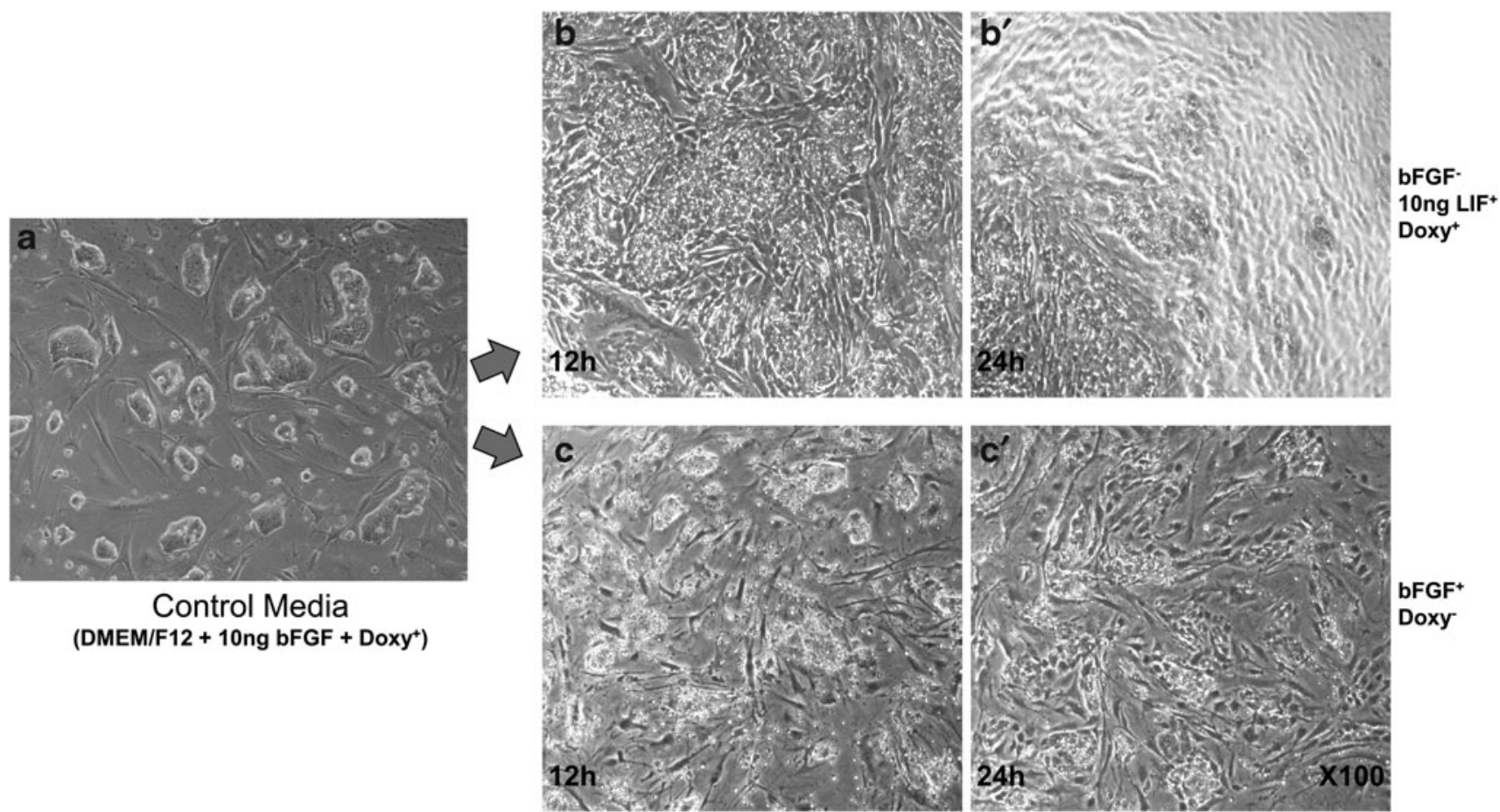

LIF

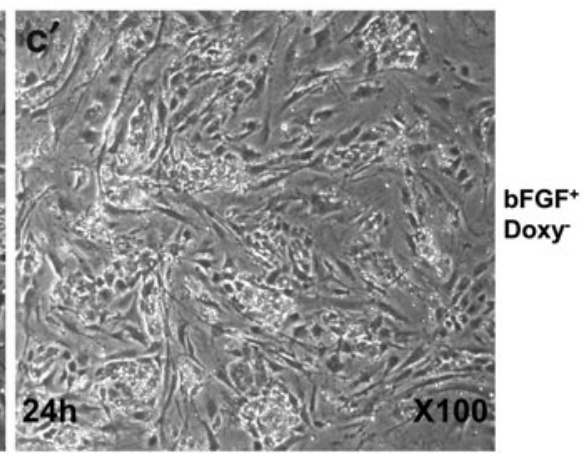

FIG. 2. The colony deformation on different media conditions. To prove the optimized culture media conditions, well-growing iPS-like cells in control media (a: DMEM/F12+10 ng bFGF + Doxy ${ }^{+}$) were changed media to LIF-containing media (b: DMEM/F12 + 10 ng hLIF + Doxy ${ }^{+}$) and absent of doxycycline media (c: DMEM/F12 + 10 ng bFGF + Doxy ${ }^{-}$. In both conditions, the colonized cells were deformed the colony margin $(\mathbf{b}, \mathbf{c})$ at 12 hours and finally lost the colony shape at 24 hours $\left(\mathbf{b}^{\prime}, \mathbf{c}^{\prime}\right)$. bFGF, basic fibroblast growth factor; DMEM, Dulbecco's Modified Eagle's medium; hLIF, humanLIF; LIF, leukemia inhibitory factor. 
compact dome-like shape (Fig. 1B-c). Over time, the iPSlike colonies grew bigger having previous form at 36 hours (Fig. 1B-d). The colonies were routinely single cell passaged every 2-3 days by Tryple (Invitrogen) and single cell grew up to a new colony (Supplementary Video S1). The generated colonies were cultured up to 37 th passages by single cell culture.

To determine whether the colonies were formed from single cells, the colonies were additionally transfected with a reporter gene (GFP); only GFP-expressing colonies were selectively cultured (Fig. 1C-a'). The GFP-expressing single cells grew and divided on the $\mathrm{CF} 1$ feeder cell layer (Fig. 1C-b'), and cells formed dome-like colonies after 48 hours of culture. The colonies expressed GFP homogeneously (Fig. 1C-c'). The results clearly demonstrated that a colony could be generated from a single cell, and that the transgenic cell had self-renewal ability.

\section{Optimization of culture media condition}

The iPS-like cells retained their morphology and had a dome-like shape, which is a typical stem cell characteristic that can be observed in control media (Fig. 2a). However, the colonies regressed to a fibroblast-like shape, losing their dome-like shape in both media (LIF-dependent medium and absence of doxycycline). In LIF-containing medium, the iPS-like cells gradually differentiated to normal fibroblast cells as before transfection (Fig. 2-b, $b^{\prime}$ ). In addition, in the absence of doxycycline, the iPS-like cells had deformed morphology during colony formation and eventually lost their pluripotent ability (Fig. 2c, c').

\section{Characterization of iPS-like cells}

To identify the characteristics of iPS-like cells, the expressions of certain pluripotent markers were evaluated by
A

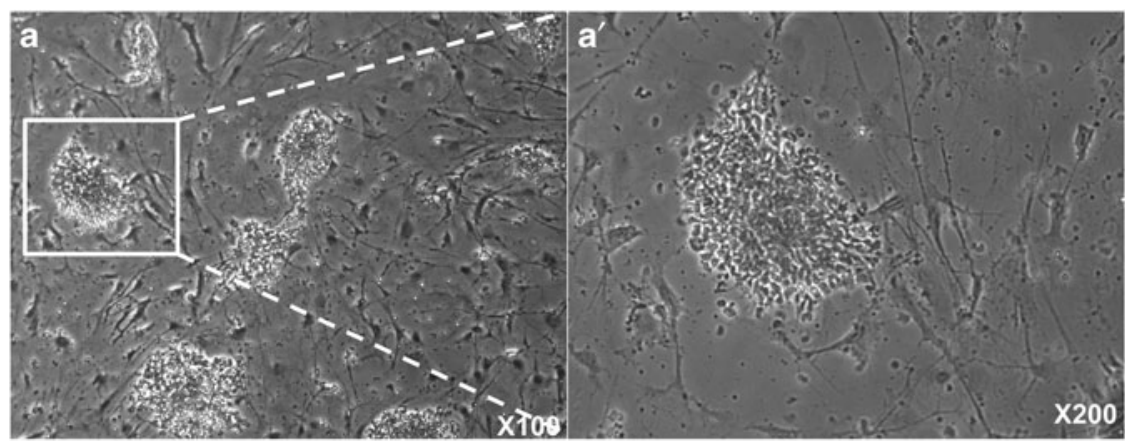

B

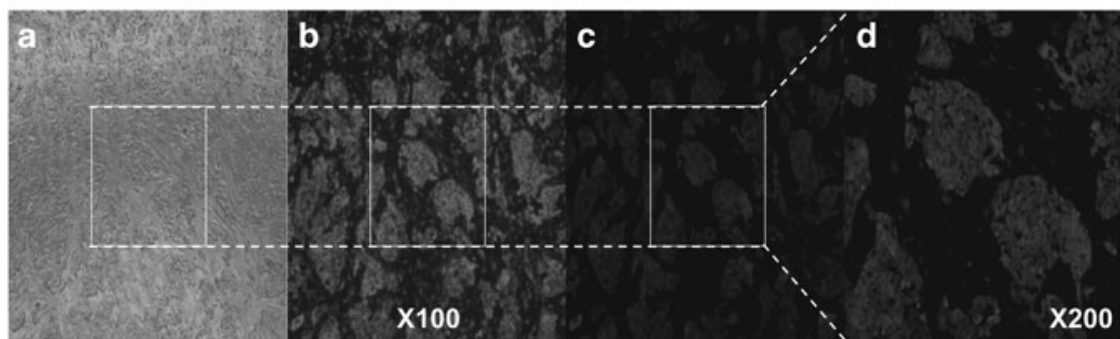

C

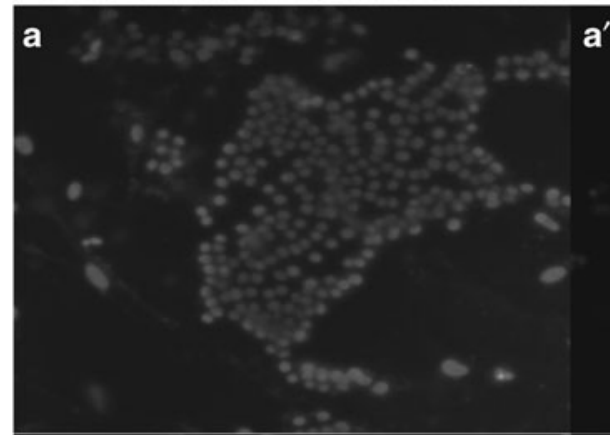

$\mathbf{a}^{\prime}$

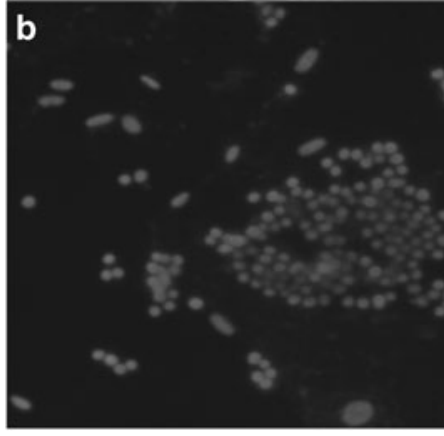

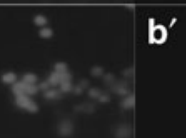

$b^{\prime}$

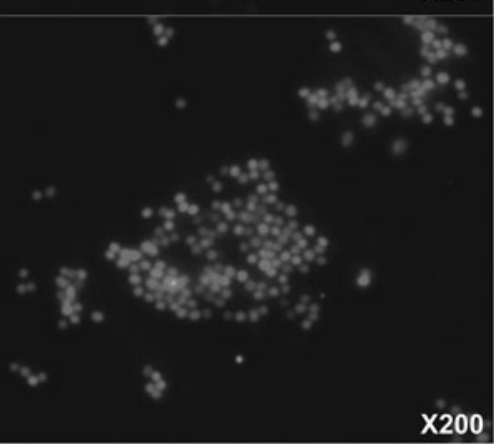

FIG. 3. Fluorescence staining pluripotency cell markers of iPSlike cells. AP was weakly stained on the surface of iPS-like cells, but it showed positive activity $\left(\mathbf{A}-\mathbf{a}, \mathbf{a}^{\prime}\right)$. It was shown from the results of CDy1 staining [B-a: brightness; B-b: nuclear staining (Dapi)] that the colonies were strongly stained with CDy1 substrate (B-c), and the stained cells correctly matched only iPS-like cells (B-d). The transfected cells strongly expressed Oct4 and Sox2 in the nucleus of cells $\left(\mathbf{C}-\mathbf{a}^{\prime}, \mathbf{b}^{\prime}\right)$. The expression aspects of Oct4 and Sox 2 correctly matched the nucleus of cells by DAPI staining $(\mathbf{C}-\mathbf{a}, \mathbf{b})$. AP, alkaline phosphatase. 
specific staining. AP and CDy1 staining showed positive results (Fig. 3A, B-c). AP and CDy 1 only stained the surface of iPS-like cells but not CF1 feeder cells. The CDy1-stained parts corresponded to the DAPI-stained cell nucleus (Fig. 3B-d).

Based on immunocytochemistry results, Oct4 and Sox2 were localized and strongly expressed in the nucleus of the established cell lines (Fig. 3C). However, other pluripotent markers including SSEA-1, SSEA-4, and Nanog were not detected.

In addition, the iPS-like stem cell colonies change the morphology into several cell types such as cuboidal, spherical, and fibroblast-like cells (Supplementary Fig. S1).

\section{Aggregation with parthenogenetic blastomeres}

The iPS-like cells demonstrated aggregation with the blastomeres of parthenogenetically activated embryos and generated chimeric blastocysts. The blastocysts, derived from the transgenic iPS-like colonies with RFP expression (Supplementary Fig. S1), were mosaically expressed in both the inner cell mass and epiblast regions (Fig. 4A-a'). However, RFP expression was not observed in normal parthenogenetically activated blastocysts (not injected cell, Fig. 4A-b'). The $\beta$-gal staining results clearly indicated that the cells were successfully aggregated with parthenogenetic blastomeres. Indigo-blue-stained parts were observed in the blastocysts and the cultured trophoblasts, which were established by seeding the blastocysts onto CF1 feeder cells (Fig. 4B-a, a').

\section{Developmental competence of SCNT-derived embryos}

To assess the developmental potential of using iPS-like cells as donors for nuclear transfer, single iPS-like cells were reconstructed with enucleated oocytes and developed into the preimplantation stage. Of 306 cloned embryos, 145 $(47.3 \% \pm 2.7 \%)$ embryos developed into the two-cell stage, and $48(15.7 \% \pm 2.3 \%)$ blastocysts were generated (Table 2$)$. The cleavage rate and blastocyst formation rate were not significantly different between fetal fibroblasts and iPS-like cells.

However, the cell number of blastocysts was significantly higher compared with that of fetal fibroblasts (47.4 \pm 3.8 vs. $36.5 \pm 2.5)$. Furthermore, the origin of blastocysts was identified by $\beta$-gal staining and the reporter gene expression of the SCNT donor cells. The generated cloned blastocysts were stained by $\beta$-gal (Fig. 5A-b, $\mathrm{b}^{\prime}$ ). In addition, GFPexpressing iPS-like cells were successfully reprogrammed to preimplantation embryos, which expressed GFP without mosaicism (Fig. 5B-b, b').

\section{Discussion}

The data demonstrated that the established iPS-like cells from fetal fibroblasts using $P B$ and porcine transcription
FIG. 4. Generation of chimeric parthenotes by transgenic cells aggregation. After injection of iPS-like cells into parthenotes (A-a), the blastocysts showed mosaic RFP expression (A-a'). Parthenote blastocysts without iPS-like cell injection did not show any fluorescence (A-b', not injected). In the results of $\beta$-gal staining, transgenic mediated-chimeric blastocysts (B-a) and -trophoblast (B-a') were showing mosaicism. iPSCs, induced pluripotent stem cells.

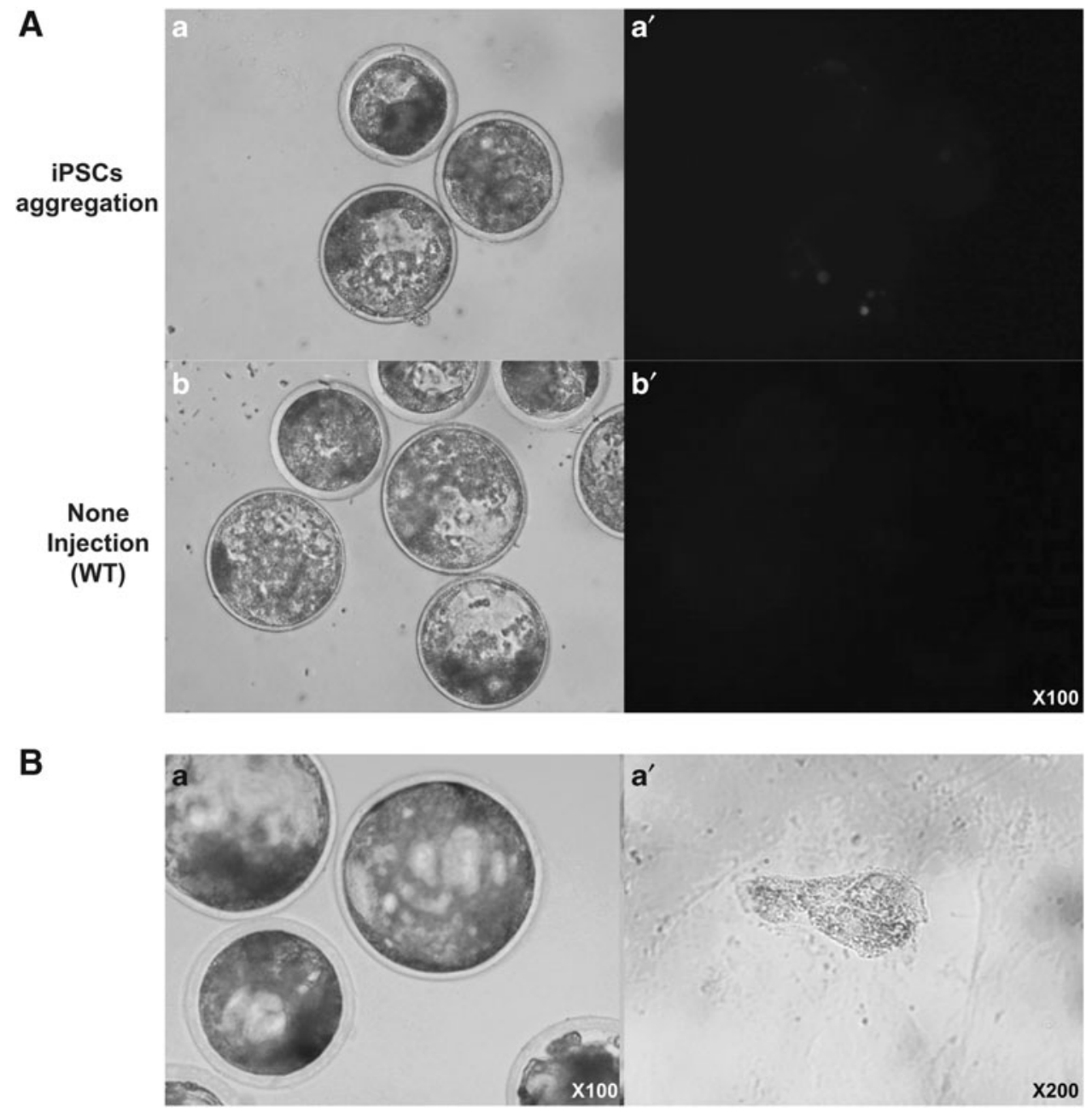


Table 2. Comparison Developmental RATe of Cloned EMBryos Derived FROM FIBROBLASTS OR IPS-LIKE CELLS

\begin{tabular}{lcccc}
\hline & $\begin{array}{c}\text { Total } \\
\text { embryo } \\
\text { Cell type }\end{array}$ & $\begin{array}{c}\text { Cleavage } \\
\text { rate (\%) }\end{array}$ & $\begin{array}{c}\text { BL } \\
\text { formation } \\
\text { rate }\end{array}$ & $\begin{array}{c}\text { Total } \\
\text { cell No. }\end{array}$ \\
\hline $\begin{array}{l}\text { Fibroblast } \\
\text { iPS-like }\end{array}$ & 503 & $44.6 \pm 3.8$ & $12.8 \pm 2.5$ & $36.5 \pm 2.5^{\mathrm{a}}$ \\
$\quad$ cell & 306 & $47.3 \pm 2.7$ & $15.7 \pm 2.3$ & $47.4 \pm 3.8^{\mathrm{b}}$ \\
& & & &
\end{tabular}

\footnotetext{
${ }^{\mathrm{a}, \mathrm{b}}$ Within the same column, values with different superscripts are significantly different $(p<0.05)$.

iPS, induced pluripotent stem.
}

factors could propagate without senescence from a single cell with self-renewal ability. In this study, pluripotent characteristics, such as self-renewal ability, dome colony formation, and rapid proliferation, were preserved during growth in the stem cell media. Pluripotent cells are categorized into primed and naïve types. Primed pluripotent cells, including mouse epiblast stem cells, human ESCs, and human iPSCs, appear as flattened colonies, have low clonogenicity, and depend on bFGF/activin for self-renewal.

Naïve stem cells, such as mouse ESCs, are tight domed colonies, are highly clonogenic from single cells, and are LIF/Stat3 dependent, with self-renewal ability (Nichols and Smith, 2009). Ambiguously, the present established iPS-like cells were not classified into these cell types as they had a compact, domed colony morphology and high clonogenicity from single cells but progress through a bFGF/activindependent self-renewal pathway.
The stem cell markers AP, Oct4, and Sox2 were detectable on the iPS-like cell surface or in the nucleus. However, the sensitivity of AP staining was low to determine whether iPS-like cells were pluripotent (Fig. 3A). Another staining substance, CDy1, was strongly detected in present iPS-like cells only, not feeder cells. On the contrary, SSEA-1, SSEA4, and Nanog were not detected. Oct4 and Sox 2 are the main key factors in stem cell whether the cell type is naïve or primed status cells. These factors should be present in the nucleus of stem cells.

However, in the case of SSEA-1 and 4, there is still controversy on their expression and role as stem cell markers in pigs. The expressions of these markers can vary according to several studies (Esteban et al., 2009; Ezashi et al., 2009; Wu et al., 2009). Studies on the expression and levels of pluripotent markers have indicated that the pluripotency of stem cells may be limited in the porcine inner cell mass. Therefore, the role of transcription factors and pluripotent marker expression in pigs remains unclear, and further studies are needed for a complete characterization.

The iPS-like cell colonies occasionally changed morphology into several cell types such as cuboidal, spherical, and fibroblast-like cells during the cell culture, as the cells have differentiation ability. Thus, we performed embryonic body (EB) formation to evaluate differentiating into three germ layers, but the iPS-like cells failed the EB formation. Although the iPS-like cells showed important features such as self-renewal and stem cell markers, they showed partial rather than full pluripotency.

Cell aggregation is another feasible method to determine pluripotency (Nakano et al., 2013). iPS-like cells (15-20
A

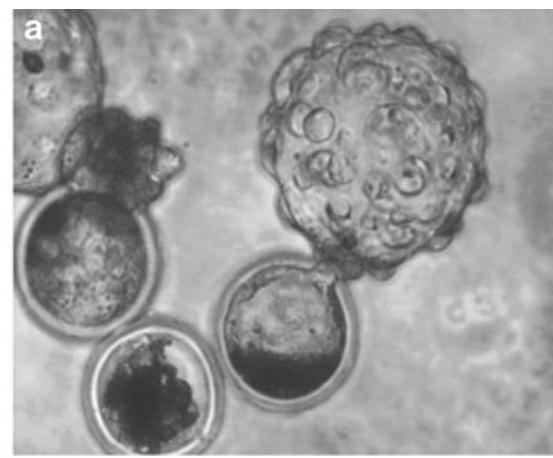

B

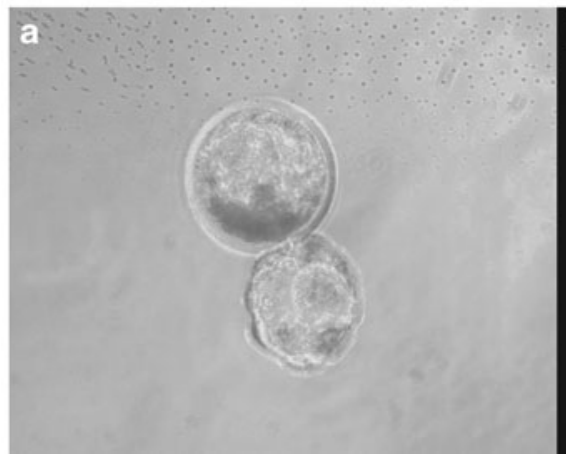

b

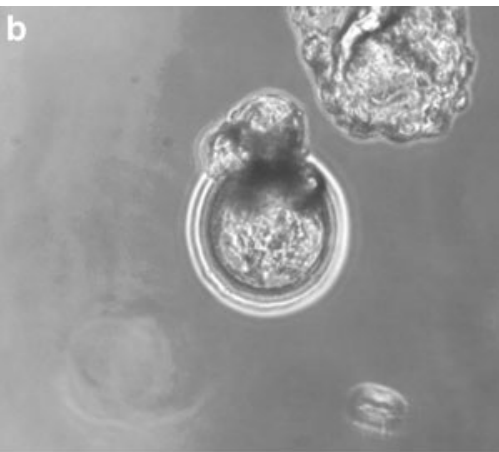

b $\mathbf{b}^{\prime}$

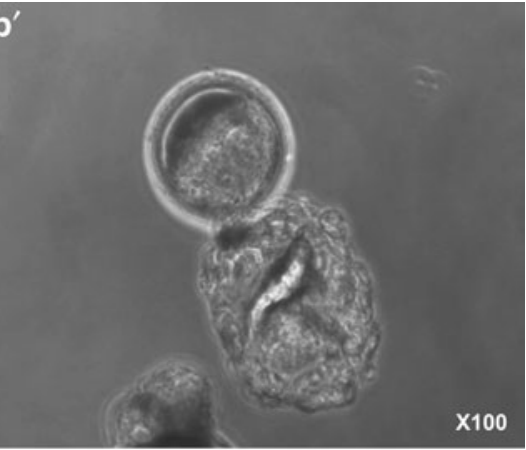

$\mathbf{b}^{\prime}$

FIG. 5. The blastocysts derived from porcine iPS-like cells by SCNT. Blastocyst development was normally observed (A-a: brightness), and the results of $\beta$-gal staining determined the origin (A-b, $\mathbf{b}^{\prime}: \beta$-gal was stained due to $\beta$-geo). SCNT blastocysts derived from GFP expressing donor cells were homologous, expressed green fluorescence protein (GFP) (B-a: brightness; B-b and B-b': fluorescence). SCNT, somatic cell nuclear transfer. 
cells) were injected into an electrically activated parthenote, and the embryos were developed into a chimeric blastocyst. The chimeric blastocysts were identified using RFPexpressing cells and $\beta$-gal staining. The iPS-like cells aggregated completely with the blastomere of the parthenote. As a result, the chimeric blastocysts expressed RFP and had indigo blue spots after $\beta$-gal staining. The established cell line must retain pluripotency without exogenous inducing factors to successfully generate iPSCs. However, the iPS-like cell line in this study did not maintain pluripotency in the absence of doxycycline, which controls the transcription of exogenously targeted DNAs in the $P B$ transposon vectors.

These results are in agreement with those of previous studies; however, the continuous expression of exogenous transcription factors is still necessary to maintain the pluripotency of presumptive iPSCs in pigs (Esteban et al., 2009; Ezashi et al., 2009; Wu et al., 2009). There have been no reports of porcine iPSCs in which the inducing factors are silenced and pluripotency is maintained by endogenous pluripotent factors (Kues et al., 2013).

The transformed cells were successfully reprogrammed into the blastocyst stage after reconstruction with pig oocytes. Furthermore, an additional gene (GFP or RFP) was transfected and expressed in preimplantation embryos without mosaicism. The iPS-like cells developed in the study can be maintained in vitro without senescence, which allows easy manipulation of another gene within the cells of large animals. Furthermore, developmental competence of the cloned embryos derived from the iPS-like cells appeared greater than that of the embryos reconstructed with fibroblasts.

In conclusion, we demonstrated that the constructed $P B$ transposon vector associated with four porcine transcription factors could be used to generate iPS-like cells, which are stained positive with some stem cell markers. These cells could potentially be used as suitable donors for generating genetically modified embryos and animals through SCNT. The cells could also be a valuable source for generating pig models for human biomedical research.

\section{Acknowledgments}

This study was financially supported by NRF (No. 20110014941), the Research Institute of Veterinary Science, and BK21 PLUS Program for Creative Veterinary Science Research.

\section{Author Disclosure Statement}

The authors declare that no conflicting financial interests exist.

\section{References}

Aigner, B., Renner, S., Kessler, B., Klymiuk, N., Kurome, M., Wunsch, A., and Wolf, E. (2010). Transgenic pigs as models for translational biomedical research. J Mol Med (Berl) 88, 653-664.

Baguisi, A., Behboodi, E., Melican, D.T., Pollock, J.S., Destrempes, M.M., Cammuso, C., Williams, J.L., Nims, S.D., Porter, C.A., Midura, P., Palacios, M.J., Ayres, S.L., Denniston, R.S., Hayes, M.L., Ziomek, C.A., Meade, H.M.,
Godke, R.A., Gavin, W.G., Overström, E.W., and Echelard, Y. (1999). Production of goats by somatic cell nuclear transfer. Nat Biotechnol 17, 456-461.

Campbell, K.H., Loi, P., Cappai, P., and Wilmut, I. (1994). Improved development to blastocyst of ovine nuclear transfer embryos reconstructed during the presumptive S-phase of enucleated activated oocytes. Biol Reprod 50, 1385-1393.

Campbell, K.H., Loi, P., Otaegui, P.J., and Wilmut, I. (1996). Cell cycle co-ordination in embryo cloning by nuclear transfer. Rev Reprod 1, 40-46.

Cao, H., Yang, P., Pu, Y., Sun, X., Yin, H., Zhang, Y., Zhang, Y., Li, Y., Liu, Y., Fang, F., Zhang, Z., Tao, Y., and Zhang, $X$. (2012). Characterization of bovine induced pluripotent stem cells by lentiviral transduction of reprogramming factor fusion proteins. Int J Biol Sci 8, 498-511.

Cibelli, J.B., Lanza, R.P., Campbell, K.H., and West, M.D. (2002). Principles of Cloning. (Academic Press, San Diego).

Ekser, B., Ezzelarab, M., Hara, H., van der Windt, D.J., Wijkstrom, M., Bottino, R., Trucco, M., and Cooper, D.K. (2012). Clinical xenotransplantation: The next medical revolution? Lancet 379, 672-683.

Ekser, B., Gridelli, B., Veroux, M., and Cooper, D.K. (2011). Clinical pig liver xenotransplantation: How far do we have to go? Xenotransplantation 18, 158-167.

Esteban, M.A., Xu, J., Yang, J., Peng, M., Qin, D., Li, W., Jiang, Z., Chen, J., Deng, K., Zhong, M., Cai, J., Lai, L., and Pei, D. (2009). Generation of induced pluripotent stem cell lines from Tibetan miniature pig. J Biol Chem 284, 1763417640.

Ezashi, T., Matsuyama, H., Telugu, B.P., and Roberts, R.M. (2011). Generation of colonies of induced trophoblast cells during standard reprogramming of porcine fibroblasts to induced pluripotent stem cells. Biol Reprod 85, 779-787.

Ezashi, T., Telugu, B.P., Alexenko, A.P., Sachdev, S., Sinha, S., and Roberts, R.M. (2009). Derivation of induced pluripotent stem cells from pig somatic cells. Proc Natl Acad Sci U S A 106, 10993-10998.

Fusaki, N., Ban, H., Nishiyama, A., Saeki, K., and Hasegawa, M. (2009). Efficient induction of transgene-free human pluripotent stem cells using a vector based on Sendai virus, an RNA virus that does not integrate into the host genome. Proc Jpn Acad Ser B Phys Biol Sci 85, 348-362.

Han, X., Han, J., Ding, F., Cao, S., Lim, S.S., Dai, Y., Zhang, R., Zhang, Y., Lim, B., and Li, N. (2011). Generation of induced pluripotent stem cells from bovine embryonic fibroblast cells. Cell Res 21, 1509-1512.

Hanna, J., Wernig, M., Markoulaki, S., Sun, C.W., Meissner, A., Cassady, J.P., Beard, C., Brambrink, T., Wu, L.C., Townes, T.M., and Jaenisch, R. (2007). Treatment of sickle cell anemia mouse model with iPS cells generated from autologous skin. Science 318, 1920-1923.

Honda, A., Hirose, M., Hatori, M., Matoba, S., Miyoshi, H., Inoue, K., and Ogura, A. (2010). Generation of induced pluripotent stem cells in rabbits: Potential experimental models for human regenerative medicine. J Biol Chem 285, 31362-31369. Imamura, M., Okuno, H., Tomioka, I., Kawamura, Y., Lin, Z.Y., Nakajima, R., Akamatsu, W., Okano, H.J., Matsuzaki, Y., Sasaki, E., and Okano, H. (2012). Derivation of induced pluripotent stem cells by retroviral gene transduction in mammalian species. Methods Mol Biol 925, 21-48.

Jeon, H.Y., Jeong, Y.W., Kim, Y.W., Jeong, Y.I., Hossein, S.M., Yang, H., Hyun, S.H., Jeung, E.B., and Hwang, W.S. (2012). Senescence is accelerated through donor cell specificity in cloned pigs. Int J Mol Med 30, 383-391. 
Kang, N.Y., Yun, S.W., Ha, H.H., Park, S.J., and Chang, Y.T. (2011). Embryonic and induced pluripotent stem cell staining and sorting with the live-cell fluorescence imaging probe CDy1. Nat Protoc 6, 1044-1052.

Kasinathan, P., Knott, J.G., Wang, Z., Jerry, D.J., and Robl, J.M. (2001). Production of calves from G1 fibroblasts. Nat Biotechnol 19, 1176-1178.

Khodadadi, K., Sumer, H., Pashaiasl, M., Lim, S., Williamson, M., and Verma, P.J. (2012). Induction of pluripotency in adult equine fibroblasts without c-MYC. Stem Cells Int 2012, 429160.

Kim, E., and Hyun, S.H. (2014). Comparative analysis of various donor cell types for somatic cell nuclear transfer and its association with apoptosis and senescence. Mol Med Rep 9, 63-68.

Kim, S., Saadeldin, I.M., Choi, W.J., Lee, S.J., Lee, W.W., Kim, B.H., Han, H.J., Bang du, H., Lee, B.C., and Jang, G. (2011). Production of transgenic bovine cloned embryos using piggybac transposition. J Vet Med Sci 73, 1453-1457.

Kim, S.J., Koo, O.J., Park, H.J., Moon, J.H., da Torre, B.R., Javaregowda, P.K., Kang, J.T., Park, S.J., Saadeldin, I.M., Choi, J.Y., Lee, B.C., and Jang, G. (2015). Oct4 overexpression facilitates proliferation of porcine fibroblasts and development of cloned embryos. Zygote 23, 704-711.

Kou, Z., Kang, L., Yuan, Y., Tao, Y., Zhang, Y., Wu, T., He, J., Wang, J., Liu, Z., and Gao, S. (2010). Mice cloned from induced pluripotent stem cells (iPSCs). Biol Reprod 83, 238243.

Kues, W.A., Herrmann, D., Barg-Kues, B., Haridoss, S., Nowak-Imialek, M., Buchholz, T., Streeck, M., Grebe, A., Grabundzija, I., Merkert, S., Martin, U., Hall, V.J., Rasmussen, M.A., Ivics, Z., Hyttel, P., and Niemann, H. (2013). Derivation and characterization of sleeping beauty transposon-mediated porcine induced pluripotent stem cells. Stem Cells Dev 22, 124-135.

Li, J., Gao, Y., Petkov, S., Purup, S., Hyttel, P., and Callesen, H. (2014). Passage number of porcine embryonic germ cells affects epigenetic status and blastocyst rate following somatic cell nuclear transfer. Anim Reprod Sci 147, 39-46.

Liu, J., Balehosur, D., Murray, B., Kelly, J.M., Sumer, H., and Verma, P.J. (2012). Generation and characterization of reprogrammed sheep induced pluripotent stem cells. Theriogenology 77, 338-346.e1.

Lorenzo, I.M., Fleischer, A., and Bachiller, D. (2013). Generation of mouse and human induced pluripotent stem cells (iPSC) from primary somatic cells. Stem Cell Rev 9, 435450.

Mizutani, E., Torikai, K., Wakayama, S., Nagatomo, H., Ohinata, Y., Kishigami, S., and Wakayama, T. (2016). Generation of cloned mice and nuclear transfer embryonic stem cell lines from urine-derived cells. Sci Rep 6, 23808.

Montserrat, N., Bahima, E.G., Batlle, L., Hafner, S., Rodrigues, A.M., Gonzalez, F., and Izpisua Belmonte, J.C. (2011). Generation of pig iPS cells: A model for cell therapy. J Cardiovasc Transl Res 4, 121-130.

Nakagawa, M., Koyanagi, M., Tanabe, K., Takahashi, K., Ichisaka, T., Aoi, T., Okita, K., Mochiduki, Y., Takizawa, N., and Yamanaka, S. (2008). Generation of induced pluripotent stem cells without Myc from mouse and human fibroblasts. Nat Biotechnol 26, 101-106.

Nakano, K., Watanabe, M., Matsunari, H., Matsuda, T., Honda, K., Maehara, M., Kanai, T., Hayashida, G., Kobayashi, M., Kuramoto, M., Arai, Y., Umeyama, K., Fujishiro, S.H., Mizukami, Y., Nagaya, M., Hanazono, Y., and Nagashima, H.
(2013). Generating porcine chimeras using inner cell mass cells and parthenogenetic preimplantation embryos. PLoS One 8, e61900.

Nichols, J., and Smith, A. (2009). Naive and primed pluripotent states. Cell Stem Cell 4, 487-492.

Oback, B., and Wells, D. (2002). Donor cells for nuclear cloning: Many are called, but few are chosen. Cloning Stem Cells 4, 147-168.

Park, I.H., Zhao, R., West, J.A., Yabuuchi, A., Huo, H., Ince, T.A., Lerou, P.H., Lensch, M.W., and Daley, G.Q. (2008). Reprogramming of human somatic cells to pluripotency with defined factors. Nature 451, 141-146.

Park, S.J., Cho, B., Koo, O.J., Kim, H., Kang, J.T., Hurh, S., Kim, S.J., Yeom, H.J., Moon, J., Lee, E.M., Choi, J.Y., Hong, J.H., Jang, G., Hwang, J.I., Yang, J., Lee, B.C., Ahn, C. (2014). Production and characterization of soluble human TNFRI-Fc and human HO-1(HMOX1) transgenic pigs by using the F2A peptide. Transgenic Res 23, 407-419.

Polejaeva, I.A., Chen, S.H., Vaught, T.D., Page, R.L., Mullins, J., Ball, S., Dai, Y., Boone, J., Walker, S., Ayares, D.L., Colman, A., and Campbell, K.H. (2000). Cloned pigs produced by nuclear transfer from adult somatic cells. Nature 407, 86-90.

Richter, A., Kurome, M., Kessler, B., Zakhartchenko, V., Klymiuk, N., Nagashima, H., Wolf, E., and Wuensch, A. (2012). Potential of primary kidney cells for somatic cell nuclear transfer mediated transgenesis in pig. BMC Biotechnol 12, 84.

Rideout, W.M., 3rd, Wakayama, T., Wutz, A., Eggan, K., Jackson-Grusby, L., Dausman, J., Yanagimachi, R., and Jaenisch, R. (2000). Generation of mice from wild-type and targeted ES cells by nuclear cloning. Nat Genet 24, 109-110.

Song, H., Li, H., Huang, M., Xu, D., Gu, C., Wang, Z., Dong, F., and Wang, F. (2013). Induced pluripotent stem cells from goat fibroblasts. Mol Reprod Dev 80, 1009-1017.

Takahashi, K., Tanabe, K., Ohnuki, M., Narita, M., Ichisaka, T., Tomoda, K., and Yamanaka, S. (2007). Induction of pluripotent stem cells from adult human fibroblasts by defined factors. Cell 131, 861-872.

Takahashi, K., and Yamanaka, S. (2006). Induction of pluripotent stem cells from mouse embryonic and adult fibroblast cultures by defined factors. Cell 126, 663-676.

Talluri, T.R., Kumar, D., Glage, S., Garrels, W., Ivics, Z., Debowski, K., Behr, R., Niemann, H., and Kues, W.A. (2015). Derivation and characterization of bovine induced pluripotent stem cells by transposon-mediated reprogramming. Cell Reprogram 17, 131-140.

Tian, X.C., Kubota, C., Enright, B., and Yang, X. (2003). Cloning animals by somatic cell nuclear transfer-Biological factors. Reprod Biol Endocrinol 1, 98.

Wakayama, T., Perry, A.C., Zuccotti, M., Johnson, K.R., and Yanagimachi, R. (1998). Full-term development of mice from enucleated oocytes injected with cumulus cell nuclei. Nature 394, 369-374.

Wakayama, T., Rodriguez, I., Perry, A.C., Yanagimachi, R., and Mombaerts, P. (1999). Mice cloned from embryonic stem cells. Proc Natl Acad Sci U S A 96, 14984-14989.

Wang, Q.H., Peng, Y., Cai, X.Y., Wan, M., Liu, Y., and Wei, H. (2015). Nucleus transfer efficiency of ear fibroblast cells isolated from Bama miniature pigs at various ages. J Huazhong Univ Sci Technolog Med Sci 35, 585-590.

Wells, D.N., Laible, G., Tucker, F.C., Miller, A.L., Oliver, J.E., Xiang, T., Forsyth, J.T., Berg, M.C., Cockrem, K., L'Huillier, P.J., Tervit, H.R., and Oback, B. (2003). Coordination be- 
tween donor cell type and cell cycle stage improves nuclear cloning efficiency in cattle. Theriogenology 59, 45-59.

West, F.D., Uhl, E.W., Liu, Y., Stowe, H., Lu, Y., Yu, P., Gallegos-Cardenas, A., Pratt, S.L., and Stice, S.L. (2011). Brief report: Chimeric pigs produced from induced pluripotent stem cells demonstrate germline transmission and no evidence of tumor formation in young pigs. Stem Cells 29, 1640-1643.

Whitworth, D.J., Ovchinnikov, D.A., Sun, J., Fortuna, P.R., and Wolvetang, E.J. (2014). Generation and characterization of leukemia inhibitory factor-dependent equine induced pluripotent stem cells from adult dermal fibroblasts. Stem Cells Dev 23, 1515-1523.

Wilmut, I., Schnieke, A.E., McWhir, J., Kind, A.J., and Campbell, K.H. (2007). Viable offspring derived from fetal and adult mammalian cells. Cloning Stem Cells 9, 3-7.

Wu, G., Liu, N., Rittelmeyer, I., Sharma, A.D., Sgodda, M., Zaehres, H., Bleidissel, M., Greber, B., Gentile, L., Han, D.W., Rudolph, C., Steinemann, D., Schambach, A., Ott, M., Schöler, H.R., and Cantz, T. (2011). Generation of healthy mice from gene-corrected disease-specific induced pluripotent stem cells. PLoS Biol 9, e1001099.

Wu, S.C., Meir, Y.J., Coates, C.J., Handler, A.M., Pelczar, P., Moisyadi, S., and Kaminski, J.M. (2006). piggyBac is a flexible and highly active transposon as compared to Sleeping Beauty, Tol2, and Mos1 in mammalian cells. Proc Natl Acad Sci U S A 103, 15008-15013.

Wu, Z., Chen, J., Ren, J., Bao, L., Liao, J., Cui, C., Rao, L., Li, H., Gu, Y., Dai, H., Zhu, H., Teng, X., Cheng, L., and Xiao, L. (2009). Generation of pig induced pluripotent stem cells with a drug-inducible system. J Mol Cell Biol 1, 46-54.

Yang, X., Smith, S.L., Tian, X.C., Lewin, H.A., Renard, J.P., and Wakayama, T. (2007). Nuclear reprogramming of cloned embryos and its implications for therapeutic cloning. Nat Genet 39, 295-302.

Yoshioka, K., Suzuki, C., Tanaka, A., Anas, I.M., and Iwamura, S. (2002). Birth of piglets derived from porcine zygotes cultured in a chemically defined medium. Biol Reprod 66, 112-119.

Yu, J., Vodyanik, M.A., Smuga-Otto, K., Antosiewicz-Bourget, J., Frane, J.L., Tian, S., Nie, J., Jonsdottir, G.A., Ruotti, V., Stewart, R., Slukvin, I.I., and Thomson, J.A. (2007). Induced pluripotent stem cell lines derived from human somatic cells. Science 318, 1917-1920.

Zheng, Y.M., Zhao, H.Y., Zhao, X.E., Quan, F.S., Hua, S., He, X.Y., Liu, J., He, X.N., and Lin, H. (2009). Development of cloned embryos from porcine neural stem cells and amniotic fluid-derived stem cells transfected with enhanced green fluorescence protein gene. Reproduction 137, 793-801.

Zhou, W., and Freed, C.R. (2009). Adenoviral gene delivery can reprogram human fibroblasts to induced pluripotent stem cells. Stem Cells 27, 2667-2674.

Address correspondence to: Goo Jang Department of Veterinary Clinical Sciences College of Veterinary Medicine Research Institute of Veterinary Science Seoul National University

1 Gwanak-ro, Gwanak-gu Seoul 08826 Republic of Korea

E-mail: snujang@snu.ac.kr 